\title{
THE LATTICE PARAMETERS AND RESIDUAL STRESSES IN BULK NANOCRYSTALLINE AND ULTRAFINE-GRAINED TITANIUM
}

\author{
Yu.M. Plotnikova, R.V. Smolianets, I.S. Braude, V.A. Moskalenko \\ B. Verkin Institute for Low Temperature Physics and Engineering of NAS of Ukraine \\ 47 Nauky Ave., Kharkiv, 61103, Ukraine \\ e-mail:plotnikova@ilt.kharkov.ua \\ Received January 20, 2017
}

Lattice parameters and residual stresses in the bulk nanocrystalline/ultrafine-grained titanium were studied by X-ray diffraction methods. The investigated samples were prepared using the method of the cryomechanical grain structure fragmentation with multiple rolling at the temperature of liquid nitrogen to the true strain value $|e|=3$. Phasic change of the $a$ and $c$ parameters has been found with increasing degree of cryoreduction. This change was stronger for the parameter $a$. The observed change parameters associated with a relative slip and twinning activity (initial cryo-reduction stage) as well as the formation of the nanocrystalline state (at higher degree of deformation). The most likely source of residual stresses arising in titanium at cryorolling is heterogeneous plastic deformation. The production of nanocrystalline / ultrafine-grained titanium using cryomechanical grain fragmentation method is accompanied by the formation of uniform compressive residual stresses in the informative deformable layer of billet.

KEY WORDS: lattice parameters, residual stresses, bulk nanocrystalline/ultrafine-grained titanium, X-ray diffraction, cryoreduction

\section{ПАРАМЕТРИ КРИСТАЛІЧНОЇ ГРАТКИ ТА ЗАЛИШКОВІ МАКРОНАПРУЖЕННЯ В ОБ'СМНОМУ НАНОКРИСТАЛІЧНОМУ ТА УЛЬТРАДРІБНОЗЕРНИСТОМУ ТИТАНІ}

Ю.М. Плотнікова, Р.В. Смолянець, І.С. Брауде, В.А. Москаленко

Фізико-технічний інститут низьких температур ім. Б.І. Веркіна НАН України, 61103, Украӥна, м. Харків, просп. Науки, 47

Параметри кристалічної гратки та залишкові макронапруження в об'ємному нанокристалічному/ультрадрібнозернистому титані були досліджені з використанням методів рентгенівської дифрактометрії. Зразки для дослідження були одержані застосувавши метод кріомеханічної фрагментації зеренної структури з багаторазовим вальцюванням при температурі рідкого азоту до істинних значень деформації $|e|=3$. Виявлена стадійна зміна параметрів $a$ і $c$ в залежності від деформації, більш сильне для $a$ параметру. Спостережувана зміна параметрів пов'язується 3 відносною активністю ковзання $\mathrm{i}$ двійникування (початковий етап кріовальцювання) та формуванням нанокристалічного стану (більш високий ступінь деформації). Найбільш вірогідним джерелом залишкових макронапружень, виникаючих в титані при кріовальцюванні, $є$ неоднорідна пластична деформація. Встановлено, що одержання нанокристалічного/ультрадрібнозернистого титану 3 використанням методу кріомеханічної фрагментації зерна супроводжується формуванням однорідних стискувальних залишкових напружень по глибині інформативного шару деформовної заготовки.

КЛЮЧОВІ СЛОВА: параметри кристалічної гратки, залишкові макронапруження, об'ємний нанокристалічний/ультрадрібнозернистий титан, рентгенівська дифрактометрія, кріодеформація

\section{ПАРАМЕТРЫ КРИСТАЛЛИЧЕСКОЙ РЕШЕТКИ И ОСТАТОЧНЫЕ МАКРОНАПРЯЖЕНИЯ В ОБЪЕМНОМ НАНОКРИСТАЛЛИЧЕСКОМ И УЛЬТРАМЕЛКОЗЕРНИСТОМ ТИТАНЕ Ю.М. Плотникова, Р.В. Смолянец, И.С. Брауде, В.А. Москаленко Физико-технический институт низких температур им. Б.И. Веркина НАН Украины} 61103, Украина, г. Харьков, просп. Науки, 47

Параметры кристаллической решетки и остаточные макронапряжения в объемном нанокристаллическом/ ультрамелкозернистом титане были изучены с использованием методов рентгеновской дифрактометрии. Образцы для исследования были получены, применив метод криомеханической фрагментации зеренной структуры с многократной прокаткой при температуре жидкого азота до истинных значений деформации $|e|=3$. Обнаружено стадийное изменение параметров $a$ и $c$ в зависимости от деформации, более сильное для параметра $a$. Наблюдаемое изменение параметров связывается с относительной активностью скольжения и двойникования (начальный этап криодеформации), а также с формированием нанокристаллического состояния (более высокая степень деформации). Наиболее вероятным источником остаточных макронапряжений возникающих в титане при криопрокатке является неоднородная пластическая деформация. Установлено, что получение нанокристаллического/ультрамелкозернистого титана с использованием метода криомеханической фрагментации зерна сопровождается формированием однородных сжимающих остаточных напряжений по глубине информативного слоя деформируемой заготовки.

КЛЮЧЕВЫЕ СЛОВА: параметры кристаллической решетки, остаточные макронапряжения, объемный нанокристаллический/ультрамелкозернистый титан, рентгеновская дифрактометрия, криодеформация

Титан и титановые сплавы обладают комплексом важных конструкционных и функциональных свойств, что определяет достаточно широкую сферу их практического использования - от аэрокосмической техники до изделий медицинского назначения. Однако низкая прочность нелегированного титана существенно 
ограничивает возможности его практического применения. Альтернативным легированию способом упрочнения, который не изменяет химический состав, улучшает функциональные свойства и сохраняет исходную плотность металла, является создание объемного структурного состояния с субмикронным/наноразмерным зерном при использовании деформационных технологий $[1,2]$.

Эффективным методом создания объемного нанокристаллического состояния в таких ГПУ металлах как титан и цирконий является метод криомеханической фрагментации зеренной структуры (КМФЗ) [3]. Данный метод, по сути, является распространением стандартных методов обработки металлов давлением (волочение, прокатка с формированием листов, лент, фасонных профилей и пр.) на область низких температур. Его физической основой является склонность данных металлов к двойникованию при криодеформации. Применив один из вариантов метода КМФЗ - прокатку при температуре жидкого азота (77 К), в работе [3] впервые был получен объемный нанокристаллический титан с унимодальной зеренной структурой $(10<d<100$ нм) при среднем размере зерен $d \approx 35$ нм.

Недавно [4,5] с использованием методов электронной просвечивающей микроскопии (ПЭМ) и рентгеноструктурного анализа (РСА) были получены данные о параметрах микроструктуры титана технической чистоты ВТ1-0, деформированного прокаткой при температуре 77 К, в условиях формирования в нем ультрамелкозернистого/нанокристаллического состояния. Об эволюции нанозеренной структуры образца в результате криодеформации судили по результатам оценки размеров зерен и областей когерентного рассеяния (ОКР) или кристаллитов и величины микродеформации. Обнаружен стадийный характер изменения размеров зерен и кристаллитов от степени криодеформации, который коррелирует с активностью деформационных мод скольжением и двойникованием.

Криопрокатка, как технологический процесс, в результате которого зерна микронного размера конвертируются в нанозерна, осуществляется при очень высоких деформирующих напряжениях и отсутствии процессов отдыха. Формирующемуся в этих условиях наноструктурному состоянию будут присущие сильные искажения кристаллической решетки и вероятные изменения ее параметров, а в полученных образцах будут возникать внутренние (остаточные) или макроскопические напряжения. С физической точки зрения образование остаточных напряжений после пластической деформации связано с необратимыми (остаточными) изменениями объема. Эти изменения объема, остающиеся после снятия нагрузки, и вызывают остаточные напряжения [6].

Остаточные напряжения оказывают существенное влияние на поведение металла под воздействием внешних нагрузок, а также на его функциональные свойства [7]. Сжимающие напряжения в поверхностном слое подвергаемых усталости деталей, как правило, считаются полезными, так как эти остаточные напряжения могут эффективно уменьшать поверхностные растягивающие напряжения до уровня, который не вызывает образование трещин или разрушения, повышают упругость изделия, выносливость, увеличивают коррозионную стойкость [8,9]. С другой стороны, остаточные напряжения растяжения могут значительно повысить эффективные уровни напряжения и привести к непредвиденным разрушениям [10]. Поэтому изучение остаточных напряжений представляет большой практический и научный интерес.

Целью настоящей работы являлось исследование параметров кристаллической решетки и остаточных внутренних напряжений (макронапряжений) с помощью рентгеновской дифрактометрии нанокристаллического/ ультрамелкозернистого титана ВТ1-0, полученного прокаткой при температуре жидкого азота до различных степеней обжатия при криопрокатке.

\section{МАТЕРИАЛ И МЕТОДИКА ИССЛЕДОВАНИЯ}

Был изучен титан технической чистоты ВТ1-0 в виде плиты промышленного изготовления толщиной 16 мм с содержанием основных примесей (масс. \%): $\mathrm{Fe} 0,06 ; \mathrm{O} 0,1 ; \mathrm{N} \mathrm{0,02;} \mathrm{C} \mathrm{0,01;} \mathrm{Н} \mathrm{0,002.} \mathrm{Объектом}$ рентгенографических исследований служили образцы с различным структурным состоянием, которые были полученные многократной прокаткой до разных степеней обжатия с использованием лабораторного прокатного стана. Перед каждым проходом образцы предварительно охлаждались в жидком азоте до температуры 77 К. Величина истинной деформации (деформации обжатия) определялась как $e=\ln \left(t_{0} / t_{\mathrm{e}}\right)\left(t_{0}\right.$ и $t_{\mathrm{e}}-$ начальная и конечная толщины листа) и варьировалась от $|e|=0,06$ до $|e|=3$.

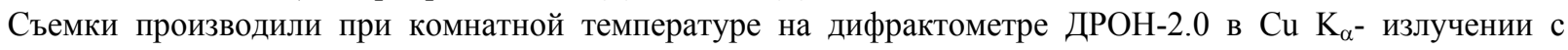
никелевым фильтром, используя набор коллимационных щелей. Распределения интенсивностей рассеяния рентгеновских лучей регистрировали в диапазоне углов $30^{\circ}<2 \theta<110^{\circ}$ с шагом сканирования $0,1^{\circ}$. Последующая обработка данных осуществлялась с помощью компьютерных программ. В качестве анализируемой была выбрана плоскость прокатки, которая не подвергалась дополнительной обработке. Это исключало возможность внесения изменений в структурное состояние в результате последующей механической обработки при более высокой (комнатной) температуре.

Параметры кристаллической решетки рассчитывались, используя метод наименьших квадратов, при этом абсолютная погрешность составляла $5 \cdot 10^{-5}$ нм. Титан, имеющий ГПУ кристаллическую решетку, характеризуется двумя параметрами: $-a$ и $c$, которые определяются согласно формуле 


$$
\frac{1}{d_{h k l}^{2}}=\frac{4}{3} \frac{h^{2}+h k+k^{2}}{a^{2}}+\frac{l^{2}}{c^{2}},
$$

где $d$ - межплоскостное расстояние плоскости $(h k l), h k l$ - индексы Миллера для анализируемой плоскости, $a$ и $c$ - параметры решетки. В данной работе вычисления осуществляли по восьми отражениям (10і10), (0002), (1011), $(10 \overline{1} 2),(10 \overline{1} 3),(20 \overline{1} 1),(0004),(10 \overline{1} 4)$.

Напряженное состояние исследовали по классическому методу $\sin ^{2} \psi$ [11]. Положение пика определяли после отделения фона и $K_{\alpha 2}$-линии дублета. Для расчета напряжений использовали отражение $(21 \overline{3} 3)$. Остаточные напряжения в выбранном направлении ф определяли по [11]:

$$
\sigma_{\varphi}=\frac{E}{1+\mu} \operatorname{tg} \alpha
$$

где $E$ - модуль нормальной упругости (модуль Юнга), $\mu$ - коэффициент Пуассона, $\operatorname{tg} \alpha$ - тангенс угла наклона прямолинейной зависимости $\theta_{\psi, \varphi}=f\left(\sin ^{2} \psi\right)$. Расчет $\theta_{\psi, \varphi}=f\left(\sin ^{2} \psi\right)$ производили по методу наименьших квадратов. Значение модуля упругости было взято как $E=110$ ГПа, а $\mu=0,32$ [12]. Размеры, вырезанных из прокатанной полосы образцов для исследования, предположительно исключали возможное влияние релаксационных процессов на уровень остаточных напряжений в анализируемой области. Погрешность определения макронапряжений не превышала 13 МПа.

\section{РЕЗУЛЬТАТЫ И ИХ ОБСУЖДЕНИЕ}

\section{Влияние криодеформации на параметры кристаллической решетки}

Сохраняющиеся после снятия силовой нагрузки внутренние напряжения вызывают упругие деформации и искажения кристаллической решетки. Рассчитанные по методу наименьших квадратов параметры кристаллической решетки титана, прокатанного при температуре 77 К до различных степеней обжатия, показаны на рис. 1. Как для параметра $a$, так и для параметра $c$ наблюдается более высокая их чувствительность к деформации на начальной стадии обжатия $(|e| \lesssim 0,6)$. На этом этапе криодеформирования увеличение параметра $a$ по отношению к исходному состоянию (изображено пунктирной линией) достигает $\gtrsim 1,2 \%$, а параметра $c$ - около $0,4 \%$ (с неравномерным характером его изменения). То есть, искажения кристаллической решетки деформационной природы сильнее влияют на параметр $a$, чем на параметр $c$.

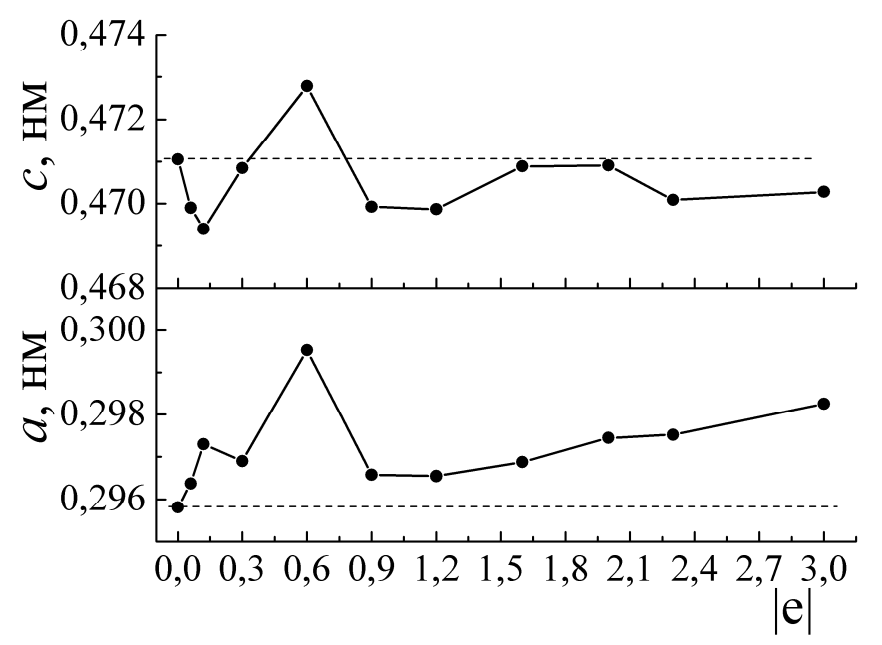

Рис. 1. Влияние степени обжатия при криопрокатке $|e|$ на параметры решетки $a$ и $c$ титана ВТ1-0

Основной причиной этому можно считать различное влияние на параметры $a$ и $c$ искажений решетки, обусловленных скольжением и двойникованием, которые имеют различные кристаллографические характеристики деформационного сдвига. Искажения решетки, вызванные призматическим скольжением, являются результатом увеличения плотности дислокаций с вектором Бюргерса $1 / 3\langle 11 \overline{2} 0\rangle$, то есть с кристаллографическим сдвигом в направлении $\langle a\rangle$. В рамках линейной теории упругости наличие дислокаций не должно сказываться на средней плотности кристалла, а соответственно, и на параметрах решетки. Однако на близком расстоянии от ядра деформации, вследствие их очень высоких значений, не могут быть описаны линейной теорией упругости. Ангармонические члены являются достаточно большими, а под действием 
гидростатического давления они вызывают дополнительную дилатацию и дислокации должны уменьшать плотность материала [13]. Возможность изменение плотности титана вследствие увеличения плотности дислокаций в результате криопрокатки была показана в работе [14]. При этом наблюдалась корреляция между закономерностями в изменении плотности $\rho$ и параметра решетки $a$ в зависимости от режимов криомеханической и термической обработок.

В то же время небольшое уменьшение параметра $c$ при криообжатии $|e|=0,12$ (рис. 1) можно объяснить возникновением двойников $\{11 \overline{2} 2\}\langle 11 \overline{2} 3\rangle$, вызывающих сжатие в направлении оси $c$ (при формирующейся в зернах ламинарной двойниковой структурой). В дальнейшем этот эффект подавляется активизацией вторичного двойникования, при котором внутри двойников сжатия увеличивается плотность двойников растяжения, вызывающих растяжение решетки в направлении оси $c$. Таким образом, тенденция в изменении параметров $a$ и с на начальной стадии обжатия при криопрокатке обусловлена искажениями кристаллической решетки, с различной кристаллографией сдвиговых деформаций.

Резкое уменьшение обоих параметров $а$ и $c$ при деформации $|e|=0,9$, а затем слабое их изменение, совпадает с формированием нанокристаллического состояния. Как косвенные, так и прямые экспериментальные результаты указывают на невозможность накопления дислокаций в зернах субмикронного и нанометрового размера. Последнее может приводить к уменьшению как плотности дислокаций в зерне, так и общей ее величины и, следовательно, к уменьшению искажений кристаллической решетки. Обычно предполагается, что пластическая деформация в таких материалах обусловлена зернограничным скольжением [15]. В этом случае можно предположить, что отражением увеличения плотности зернограничных 〈a〉 дислокаций является, опять-таки, более заметный рост параметра $a$.

\section{Остаточные внутренние напряжения}

Под остаточными внутренними напряжениями или макронапряжениями понимаются внутренние напряжения, возникающие в титановом прокате после обжатия при температуре жидкого азота и сохраняющиеся после окончания криомеханической обработки и отогрева до комнатной температуры. При определении полей остаточных внутренних напряжений с использованием рентгеноструктурного анализа масштабом измерения деформации является межплоскостное расстояние $d$ кристаллографических плоскостей $(h k l)[11]$. Являясь одним из важнейших параметров структурного состояния деформированного материала, остаточные макронапряжения характеризуются сжатием или растяжением кристаллической решетки. Они приводят к изменению межплоскостных расстояний на величину $\Delta d$, а, следовательно, и к смещению дифракционных линий на угол $\Delta \theta$. В связи с обнаруженными ранее изменениями параметров решетки можно ожидать изменения внутренних остаточных напряжений в зависимости от степени обжатия при криопрокатке.

На рис. 2 представлены результаты по влиянию степени обжатия при криопрокатке $|e|$ на остаточные внутренние напряжения $\sigma$, рассчитанные согласно формуле (2). Видно, что в исходном материале эти напряжения являются сжимающими, как следствие технологического процесса изготовления плиты (горячая прокатка плюс отжиг). При криопрокатке начальная степень обжатия $(|e| \lesssim 0,12)$ вызывает рост сжимающих макронапряжений, после чего наблюдается их существенное уменьшение. Величина $\sigma$ изменяется с 420 МПа до 200 МПа. В итоге можно считать, что при $|e| \gtrsim 0,6$ степень криодеформации не влияет на уровень остаточных внутренних напряжений. Среднее значение $\sigma$ составляет 240 МПа (рис. 2).

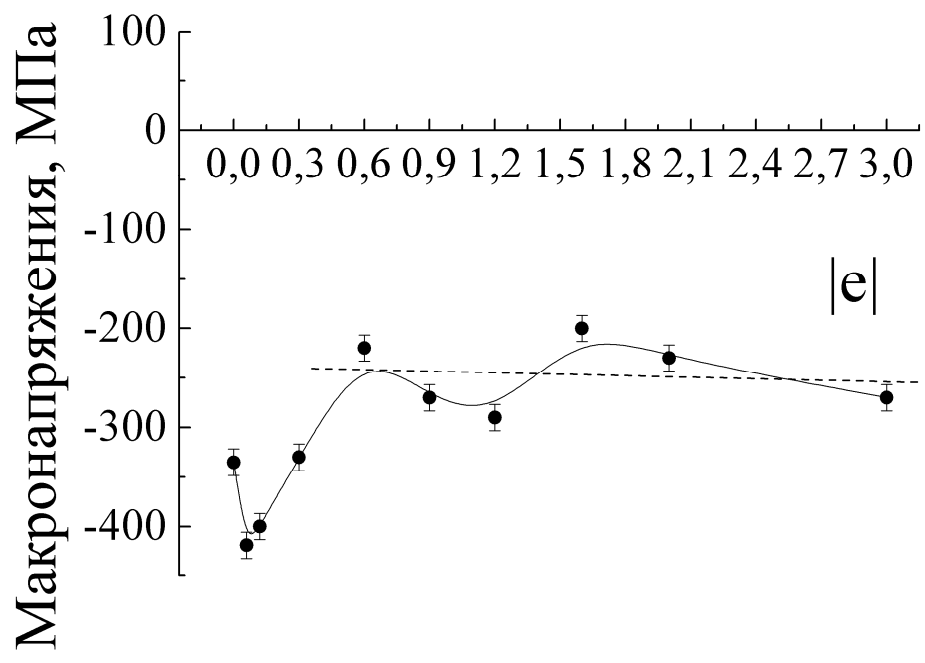

Рис. 2. Влияние степени обжатия при криопрокатке $|e|$ на величину остаточных внутренних напряжений $\sigma$ в полосе титана ВТ1-0 
В поликристаллических металлических материалах условием возникновения остаточных макронапряжений является протекание неоднородного изменения удельного объема. Основными источниками такой неоднородности являются неоднородная пластическая деформация, неоднородное протекание фазовых и структурных превращений, инициированных внутренними напряжениями, наличие градиента тепловых полей. Рассмотрим возможность проявления каждого из них в полосе титана технической чистоты, который подвергался указанному выше режиму криодеформации (многократной криопрокатке).

Нелегированный титан при температуре ниже 1155 К состоит из $\alpha$-фазы с гексагональной плотноупакованной решеткой [12]. Отсутствие каких-либо фазовых превращений в процессе криодеформации обжатием до $|e|=3$ было подтверждено в предыдущей работе [4] при анализе дифракционных картин. Однородный температурный режим в объеме образца во время криопрокатки обеспечивался выполнением следующих условий эксперимента. Охлажденный в жидком азоте, образец в течение короткого времени (не более 3 секунд) помещался между валками. При этом конденсирующаяся на поверхности образца пленка жидкого воздуха экранировала температурное воздействие окружающей среды в течение всего периода прокатки. В зависимости от длины образца время прокатки составляло не более 3 секунд. Передачей тепла от валков образцу в этом случае можно пренебречь. С другой стороны, при выполнении условий адиабатичности заметного повышения температуры можно ожидать за счет перехода механической энергии пластической деформации в тепловую энергию. Оценка локального повышения температуры $\Delta T$ в зоне деформации была выполнена согласно соотношению

$$
\Delta T=\left(\frac{\beta}{\rho C_{p}}\right) \int_{0}^{e} \sigma d e .
$$

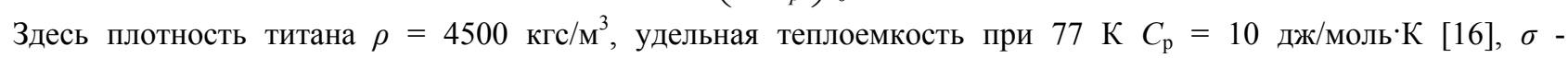
деформирующее напряжение при $77 \mathrm{~K}$, истинная деформация в течение одного прохода $e=(0,005-0,05)$ и $\beta=0,9$ - доля механической энергии пластической деформации преобразованной в тепло. Видно, что локальное повышение температуры $\Delta T$ будет зависеть от величины истинной деформации при обжатии и уровня деформирующего напряжения. Строго говоря, обе величины существенно изменяются в процессе многопроходного цикла при формировании ультрамелкозернистого/нанокристаллического состояния.

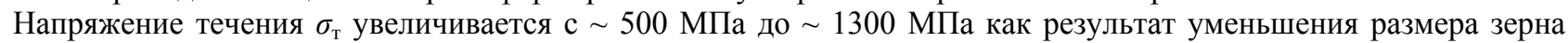
[17] в соответствии с соотношением Холла-Петча. Истинная деформация $е$ при сохранении степени обжатия за один проход $\Delta t=0,1-0,2$ мм изменялась в результате уменьшения толщины прокатываемой полосы $t_{\mathrm{e}}$, как следствие способа ее определения (смотри выше). Было установлено, что при выполнении условий адиабатичности повышение температуры $\Delta T$ может составлять $2-11 \mathrm{~K}$, что есть достаточно малой величиной. Смещаясь вдоль образца, зона повышенной температуры под валками обеспечивает выравнивание теплового поля в объеме образца в течение короткого времени прокатки.

Таким образом, наиболее вероятным источником остаточных макронапряжений является неоднородная пластическая деформация, вызванная упругопластической деформацией под нагрузкой, когда одна из частей тела деформируется упруго, а другая - пластически [11]. Этот случай реализуется при обработке металлов давлением, то есть прокатке, штамповке и др. В исследуемом прокате нанокристаллического/ ультрамелкозернистого титана средняя величина остаточных напряжений $\sigma$ во всем изученном диапазоне криодеформации остается практически неизменной (рис. 2). Уровень сжимающих остаточных напряжений составляет $\sigma \approx 240$ МПа. Такая тенденция свидетельствует о достаточно равномерной деформации по толщине образца в процессе обжатия при криопрокатке. То есть, технологическая обработка металла с использованием метода КМФЗ сопровождается формированием однородных сжимающих остаточных напряжений по глубине информативного слоя деформируемой заготовки.

\section{ЗАКЛЮЧЕНИЕ}

К наиболее успешному и перспективному в получении объемного нанокристаллического титана относится метод криомеханической фрагментации зерна, одним из вариантов которого является прокатка при температуре жидкого азота. Используя методы рентгеновской дифрактометрии, были изучены параметры кристаллической решетки и остаточные напряжения в прокате нанокристаллического/ ультрамелкозернистого титана, полученного последовательным обжатием до истинной деформации $|e|=3$. На этапе обжатия до $|e| \lesssim 0,6$ возникающие деформационные искажения приводят к заметным изменениям параметров кристаллической решетки. Параметр $a$ по сравнению с исходным состоянием увеличивается более, чем на $1,2 \%$, а параметр $c-$ на $\sim 0,4 \%$. Эти изменения параметра $a$ обусловлены, прежде всего, существенным увеличением плотности $\langle a\rangle$ дислокаций. Более слабое изменение параметра $c$ связано с кристаллографией деформации двойникованием. Резкое уменьшение обоих параметров $a$ и $c$ при $|e|=0,9$ и слабое их изменение в дальнейшем при более высоких степенях обжатия при криопрокатке связано с формированием нанокристаллического состояния и изменением механизма пластической деформации. 
Наиболее вероятным источником остаточных напряжений, которые возникают в титане при криопрокатке, является неоднородная пластическая деформация, вызванная упругопластической деформацией под нагрузкой. Эти напряжения являются сжимающими, они практически не изменяется со степенью обжатия. Их величина составляет $\approx 240$ МПа. Такая тенденция свидетельствует о достаточно равномерной деформации по толщине образца в процессе криодеформации. Таким образом, технологическая обработка титана с целью получения нанокристаллического состояния при использовании метода КМФЗ сопровождается формированием однородных сжимающих остаточных напряжений по глубине информативного слоя деформируемой заготовки.

\section{СПИСОК ЛИТЕРАТУРЫ}

1. Meyers M.A., Mishra A., Benson D.I. Mechanical properties of nanocrystalline materials // Prog. Mater. Sci. - 2006. - Vol. 51. - P.427.

2. Kutniy K.V., Volchok O.I., Kislyak I.F., Tikhonovsky M.A., Storozhilov G.E. Obtaining of pure nanostructured titanium for medicine by severe deformation at cryogenic temperatures // Mater. Sci. and Eng. Technolog. - 2011. - Vol. 42. - No. 2. P. 114-117.

3. Moskalenko V.A., Smirnov A.R., Moskalenko A.V. Cryomechanically obtained nanocrystalline titanium: microstructure and mechanical mechanical properties // Low Temp. Phys. - 2009. - Vol. 35. - P.905-907.

4. Plotnikova Yu.M., Braude I.S., Moskalenko V.A. X-ray parameters of a nanocrystalline titanium microstructure, obtained via cryodeformation // Low Temp. Phys. - 2016. - Vol. 42. - P. 1175-1180.

5. Moskalenko V.A., Smirnov A.R., Smolianets R.V. Low-temperature plastic deformation and strain-hardening of nanocrystalline titanium // Low Temp. Phys. - 2014. - Vol. 40. - P. 837-845.

6. Birger I.A. Ostatochnyye napryazheniya [Residual stresses]. - M.: Mashgiz, 1963. - 232p. (In Russian)

7. Wroński M., Wierzbanowski K., Wrybel M., Wroński S., Bacroix B. Effect of rolling asymmetry on selected properties of Grade 2 // Met. Mater. Int. - 2015. - Vol. 21. - No. 5. - P. 805-814.

8. Noyan I.C., Cohen J.B. An X-ray diffraction study of the residual stress-strain distributions in shot-peened two-phase brass // Mater. Sci. Eng. - 1985. - Vol. 75. - P. 179-193.

9. De los Rios E.R., Walley A., Milan M.T., Hammersley G. Fatigue crack initiation and propagation on shot-peened surfaces in A316 stainless steel // Int. J. Fatigue. - 1995. - Vol. 17. - P. 493-499.

10. Wu T., Hartley C.S., Wang X.M., Tsai C.T. Residual stress distribution in cold rolled brass sheet // J. Mater. Process. Technol. - 1994. - Vol. 45. - P. 111-116.

11. Gladkikh L.I., Malykhin S.V., Pugachev A.T. Difraktsionnyye metody analiza vnutrennikh napryazheniy. Teoriya i eksperiment: Ucheb. Posobiye [Diffraction methods for analysis of internal stresses. Theory and experiment: Handbook]. Khar'kov: NTU «KHPI», 2006. - 304p. (In Russian)

12. Tsvikker U. Titan i yego splavy [Titanium and its alloys]. - Moskva: Metallurgiya, 1979. - 512p. (In Russian)

13. Friedel J. Dislocations. - Moskva: Mir, 1967. - 600 s.

14. Moskalenko V.A., Betekhtin V.I., Kardashev B.K., Kadomtsev A.G., Smirnov A.R., Smolyanets R.V., Narykova V.V. Mechanical properties and Structures of Nanocrystalline titanium produced by cryorolling // Physics Solid State. - 2014. Vol. 56. - No. 81. - P. 1590-1596.

15. Zhu Y.T., Liao X.Z., Wu X.L. Deformation twinning in nanocrystalline materials // Prog. Mater. Sci. - 2012. - Vol. 57. P. 1-62.

16. Tablicy fizigheskih velichin [Tables of physical quantities.]. Ed. Akad. I.K. Kikoin. - M.: Atomizdat, 1976. - 1008p. (in Russian)

17. Moskalenko V.A., Smirnov A.R., Smolianets R.V. Low-temperature plastic deformation and strain-hardening of nanocrystalline titanium // Low Temp. Phys. - 2014. - Vol. 40. - P.837 - 845. 